\title{
Assessment of the scientific output of Hospital de Niños Pedro de Elizalde, 2000-2011
}

\author{
Paula Domínguez, M.D., ${ }^{a}$ María José Chiolo, M.D., ${ }^{a}$ \\ María Carolina Davenport, M.D., ${ }^{a}$ Sandra Di Lalla, M.D., ${ }^{a}$ Andrea Martins, M.D., \\ and Fernando Ferrero, M.D. ${ }^{a}$
}

\begin{abstract}
1ntroduction. Monitoring article submissions and publications developed by an institution is a suitable measure to assess its scientific output. Objectives. To estimate the proportion of research projects that were completed and had results submitted/published by a pediatric hospital; to describe research project design and characteristics; to outline limitations on research development or dissemination.

Methods. Descriptive and analytical study including scientific studies approved to be developed between 2000 and 2011. Each investigator was contacted and asked to participate in a survey on research development, result dissemination and possible reasons for not completing or disseminating a study.

Results. The survey was completed by the authors of 197 projects (60.9\% completed, $16.2 \%$ ongoing, $12.7 \%$ cancelled, and $10.2 \%$ put off). Drug trials were most likely not to be completed. Of all completed projects $(n=120)$, $45.8 \%$ were clinical research studies, $43.3 \%$ were epidemiological studies, and $10 \%$ were related to health services. When analyzed by design, $77.5 \%$ were observational studies while $22.5 \%$ were experimental ones.

In terms of scope, $69.1 \%$ were restricted to the hospital, $16.6 \%$ were international multicenter studies, and $14.1 \%$ were national multicenter studies. Only $36.6 \%$ of projects received funding. Lack of time (20\%) and insufficient sample size $(10 \%)$ were the most commonly indicated reasons for non dissemination. A total of $78.3 \%$ of projects were presented in conferences and $37.5 \%$ were published. The presence of funding was the only independent predictor of publication.

Conclusions. Of all approved projects, $60.9 \%$ were completed; of them, $78.3 \%$ were presented in conferences and $37.5 \%$ were published. Drug trials were most likely not to be completed, and funded studies had more chances of being published.

Key words: medical bibliography, periodic publications, research report.
\end{abstract}

http:/ /dx.doi.org/10.5546/aap.2014.eng.147

E-mail Address:

Paula Domínguez,

M.D.:

pau.dom@gmail.com

Conflict of Interest:

None.

Received: 6-4-2013

Accepted: 9-4-2013
The publication of a scientific article is the ultimate objective of any research project because it provides value and significance to any gained knowledge. Non publication is a hurdle for the dissemination of results to the scientific community and their extrapolation to the clinical practice. ${ }^{2}$ Just as the indicators of care (bed turnover, hospital discharges, length of stay, etc.) are monitored, the scientific output of an institution should also be assessed to check the adequacy of its programs.

Monitoring article submissions and publications developed by an institution is a suitable measure to assess its scientific output. At Hospital General de Niños Pedro de Elizalde, projects presented in national ${ }^{3}$ and international ${ }^{4}$ conferences and their inclusion in the publications by the most relevant national pediatric scientific journal had been assessed on another occasions. ${ }^{5}$

However, in order to make a more accurate evaluation of the scientific output of an institution, it is also necessary to know the proportion of articles developed at such facility that are actually disseminated and published.

In addition, barriers that hurdle the completion of a research project may occur across the different stages of an investigation (project preparation, institutional authorization, development, conduct, and result dissemination). ${ }^{2,6} \mathrm{~A}$ timely identification of such barriers may help to design strategies that facilitate the execution of research.

\section{OBJECTIVES}

To estimate the proportion of research projects approved by the 
institutional review board of a children's hospital between 2000 and 2011 that were completed and had their results submitted/published (presented in scientific meetings or published in a scientific journal), and to describe the study design and characteristics.

To describe the conditions referred by authors as limitations for research development or dissemination.

\section{METHODS}

Descriptive and analytical study including all scientific studies approved to be developed at the Hospital General de Niños Pedro de Elizalde (HGNPE) between January 2000 and December 2011. The investigator responsible for each project was identified using the research cards registered in the study period at the hospital Teaching and Research Committee (CODEI). Each investigator was contacted in person, by e-mail or by telephone between December 2012 and April 2013, and they were asked to take part in a short survey.

The survey was self-administered and included closed-ended questions on research development (completed, ongoing, put off, cancelled) and result dissemination (presented in a scientific meeting or published). Besides, the survey asked about the most relevant reasons for not completing or disseminating an investigation (lack of interest, lack of time, disagreement among co-authors, other articles showing similar results, results considered not significant, insufficient sample size, difficulties with statistical analysis, authors' pessimism regarding publication acceptance, funding related problems, rejected publications, and others).

Questions admitted only one possible answer (see electronic version Annex).

Additionally, the following data were obtained from the research cards: date of submission to the CODEI, department where the principal investigator worked, source of funding (national or foreign, public or private sector, pharmaceutical industry), scope (international multicenter, national multicenter, restricted to a hospital), research type (basic, clinical, social science, epidemiology, health services, animal testing), design (observational or experimental; observational studies were sub-divided into descriptive and analytical types, including crosssectional, case-control, and cohort studies, while experimental studies were sub-divided into drug trials [phase I, II, III or IV] and non-drug trials).
Data obtained from the surveys were related to data from the research cards, and they were entered into a spreadsheet, conveniently dissociated from the investigators' personal data.

\section{Statistical analysis}

Categorical outcome measures were expressed as percentages; $95 \%$ confidence intervals $(\mathrm{CI})$ are included in the main results. The $\chi^{2}$ test was used to assess the association between result dissemination (publication) and project characteristics (research type, design, scope, funding); all potential predictors were included in a logistics regression model. OR and 95\% CI were calculated. In all cases, the level of significance was set at $p<0.05$. The statistical analysis was done using the SPSS software version 11.5 (SPSS Inc., Chicago, USA, 2002).

\section{Ethical considerations}

The study was conducted in compliance with Law 25326 (Personal Data Protection), which warrants the non identification of subjects and dissociation of data. Also, the survey stated the scope of this research and informed subjects that their participation implied their acceptance of the conditions. Approval was obtained from the hospital Teaching and Research Committee and Research Ethics Committee. The study was registered at the Research Registry of the City of Buenos Aires under number 855/2010.

\section{RESULTS}

Over the study period, the hospital Teaching and Research Committee (CODEI) approved 216 research projects, and all investigators involved were invited to take part in this study. The survey was completed by 197 (91.2\%) of them.

The following are the hospital departments that submitted more than five projects over the study period: CODEI (58), Nutrition (19), Rheumatology (18), Health Promotion and Protection (15), Clinical Medicine (15), Hematology (10), and Mental Health, Cardiology, Pulmonology and Immunology (6 each). Of the remaining departments included in the study, 2 had submitted 5 projects, 1 department had submitted 4,1 had submitted 3, 5 had submitted 2, and 11 departments had submitted 1 project.

The lowest number of research projects were presented in 2001 and 2003 (3 projects), while 2009 was the year when most projects were submitted (36 projects) (Table 1). 
At the time of the survey, $120(60.9 \% ; 95 \%$ CI: 53.7-67.7) studies had been completed, 32 (16.2\%) were ongoing, $25(12.7 \%)$ had been cancelled, and $20(10.2 \%)$ were put off.

Of all completed projects $(n=120), 45.8 \%(95 \%$ CI: 36.8-55.1) were clinical research studies, $43.3 \%$ were epidemiological studies, and $10 \%$ were related to health services. In terms of design, 93 were observational (23 descriptive, 54 crosssectional analytical, 12 cohort and 4 case-control studies), while 27 were experimental (20 drug trials). In relation to the scope of protocols, 83 $(69.1 \%)$ were restricted to the hospital, 20 (16.6\%) were international multicenter studies, and 17 $(14.1 \%)$ were national multicenter studies. Only $44(36.6 \%)$ projects received funding: 21 from national sources and 23 from foreign sources. Of all projects that had received funding, 19 were funded by the pharmaceutical industry.

The results of 94 completed studies $(78.3 \%$; 95\% CI: 69.7-85.1) were presented in scientific meetings, even 34 of them were presented in international events.

Of all completed studies, 45 (37.5\%; 95\% CI: 29.0-46.8) were fully published, 25 in national scientific journals (15 in Archivos Argentinos de Pediatría) and 20 in international publications (including 3 in the New England Journal of Medicine, 2 in Pediatrics, 2 in The Pediatrics Infectious Diseases Journal, 2 in Pediatric Pulmonology). The average period between project submission and publication was $41.1 \pm 29.9$ months (median $=36$ months; interquartile range: 16.5 56.5).
Lack of time (20\%) and insufficient sample size $(10 \%)$, followed by disagreement among coauthors, considering results insignificant, and problems with statistical analysis $(6.7 \%$ each) were the most commonly described reasons for not disseminating completed studies. No investigator indicated editorial rejection as a reason for not publishing the study.

When considering research type, design, scope, funding and funds provided by the pharmaceutical industry, only a multicenter scope and receiving funds were predictors for publication (Table 2). The multivariate analysis showed that only the presence of funding was an independent predictor for publication (Table 3).

The analysis of put off or cancelled studies $(n=45)$ verified that $60 \%$ corresponded to clinical research projects, $26.6 \%$ were epidemiological studies, and $6.6 \%$ were related to health services (the remaining $6.8 \%$ of projects were social science research and animal testing). In terms of design, 27 were observational studies (6 descriptive, 12 cross-sectional analytical, and 9 cohort studies) and 18 were experimental ones (14 drug trials). In relation to the scope of protocols, 26 were restricted to the hospital, 13 were international multicenter studies, and 6 were national multicenter studies. Only 22 projects were funded, 13 of them receiving funds from the pharmaceutical industry.

The comparison between completed studies and put off/cancelled studies demonstrated that drug trials have a higher risk of remaining unpublished (Table 4).

TABLE 1. Distribution of submitted, completed and published research projects by year of submission

\begin{tabular}{|c|c|c|c|c|c|c|c|}
\hline \multirow[t]{2}{*}{ Year } & \multicolumn{2}{|c|}{ Submitted } & \multirow[t]{2}{*}{ Completed } & \multirow[t]{2}{*}{ Ongoing } & \multirow[t]{2}{*}{ Put off } & \multirow[t]{2}{*}{ Cancelled } & \multirow[t]{2}{*}{ Published } \\
\hline & $\mathbf{n}$ & $\%$ & & & & & \\
\hline 2000 & 11 & 5.6 & 9 & 1 & 1 & - & 4 \\
\hline 2001 & 3 & 1.5 & 2 & - & 1 & - & 0 \\
\hline 2002 & 4 & 2.0 & 3 & - & 1 & - & 2 \\
\hline 2003 & 3 & 1.5 & 2 & - & 1 & - & 0 \\
\hline 2004 & 10 & 5.1 & 5 & - & 3 & 2 & 1 \\
\hline 2005 & 8 & 4.1 & 7 & - & 1 & - & 7 \\
\hline 2006 & 16 & 8.1 & 11 & 1 & 4 & - & 9 \\
\hline 2007 & 31 & 15.7 & 20 & 3 & 5 & 3 & 7 \\
\hline 2008 & 18 & 9.1 & 8 & 4 & 3 & 3 & 4 \\
\hline 2009 & 36 & 18.3 & 23 & 5 & 2 & 6 & 7 \\
\hline 2010 & 25 & 12.7 & 17 & 5 & 1 & 2 & 2 \\
\hline \multirow[t]{2}{*}{2011} & 32 & 16.2 & 13 & 13 & 2 & 4 & 2 \\
\hline & 197 & 100 & 120 & 32 & 25 & 20 & 45 \\
\hline
\end{tabular}




\section{DISCUSSION}

In our study, $60 \%$ of assessed projects had been completed and $16 \%$ were ongoing. Of all completed studies, $78.3 \%$ were presented in scientific meetings and $37.5 \%$ were fully published. These data are consistent with those observed by Rodríguez, et al. ${ }^{2}$ in their study on research projects submitted in a children's hospital, submission and publication rates are $84 \%$ and $47 \%$, respectively. Although no studies assessing the scientific output from an IRB view were found, difficulties related with publication have been widely considered when comparing the proportion of abstracts presented in scientific meetings that are eventually published as a full article. $^{7,8}$

In terms of the journal where articles are published, 60\% were included in Argentine Archives of Pediatrics. This could be related to the fact that authors opt for sending their manuscripts to the most locally renown specialty journal with the greatest circulation, although language could also be a factor taken into consideration by authors in their intent to publish. ${ }^{9}$

In our study, the average time between submission to the CODEI and publication was

TABLE 2. Distribution of some characteristics of completed research projects $(n=120)$, as per publication status

\begin{tabular}{|c|c|c|c|c|c|c|}
\hline \multirow[t]{3}{*}{ Outcome measure } & \multicolumn{4}{|c|}{ Published } & \multirow{3}{*}{$\mathrm{p}$} & \multirow{3}{*}{ OR } \\
\hline & \multicolumn{2}{|c|}{ Yes $(n=45)$} & \multicolumn{2}{|c|}{ No $(n=75)$} & & \\
\hline & $\mathbf{N}$ & $\%$ & $\mathbf{n}$ & $\%$ & & \\
\hline Clinical research & 25 & 55.5 & 30 & 40 & 0.09 & $1.87(0.88-3.96)$ \\
\hline Experimental design & 10 & 22.2 & 17 & 22.6 & 0.95 & $0.97(0.40-2.36)$ \\
\hline Multicenter scope & 19 & 42.2 & 18 & 24 & 0.03 & $2.31(1.04-5.12)$ \\
\hline Funded & 26 & 57.7 & 18 & 24 & 0.0002 & $4.3(1.95-9.58)$ \\
\hline $\begin{array}{l}\text { Funded by the } \\
\text { pharmaceutical industry }\end{array}$ & 8 & 17.7 & 11 & 14.6 & 0.65 & $1.25(0.46-3.40)$ \\
\hline
\end{tabular}

TABLE 3. Logistics regression model including outcome measures that could be related to the publication of study results

\begin{tabular}{lcccc}
\hline Outcome measure & \multirow{2}{*}{ Significance } & \multirow{2}{*}{ OR } & \multicolumn{2}{c}{$\mathbf{9 5 \%}$ CI } \\
Inferior & Superior \\
\hline Clinical research & & & 0.609 & 3.835 \\
Experimental design & 0.366 & 1.528 & 0.231 & 2.779 \\
Multicenter scope & 0.726 & 0.80 & 0.415 & 3.512 \\
Funded & 0.73 & 1.207 & 1.973 & 20.628 \\
Funded by the pharmaceutical industry & $\mathbf{0 . 0 0 2}$ & 6.380 & 0.059 & 1.301 \\
\hline
\end{tabular}

Hosmer-Lemeshow test: 0.995.

TABLE 4. Distribution of some characteristics of research projects. as per completion status

\begin{tabular}{|c|c|c|c|c|c|c|}
\hline \multirow[t]{2}{*}{ Outcome measure } & \multicolumn{2}{|c|}{$\begin{array}{l}\text { Completed } \\
(n=120)\end{array}$} & \multicolumn{2}{|c|}{$\begin{array}{c}\text { Put off/ } \\
\text { cancelled }(n=45)\end{array}$} & \multirow[t]{2}{*}{$p$} & \multirow[t]{2}{*}{ OR } \\
\hline & $n$ & $\%$ & $n$ & $\%$ & & \\
\hline Clinical research & 55 & 45.8 & 27 & 60 & 0.1 & $0.56(0.28-1.13)$ \\
\hline $\begin{array}{l}\text { Experimental design } \\
\text { with drugs }\end{array}$ & 20 & 16.6 & 14 & 31.1 & 0.04 & $0.44(0.20-0.97)$ \\
\hline Multicenter scope & 37 & 30.8 & 19 & 42.2 & 0.16 & $0.61(0.30-1.23)$ \\
\hline Funded & 44 & 36.6 & 22 & 48.8 & 0.15 & $0.60(0.30-1.20)$ \\
\hline $\begin{array}{l}\text { Funded by the } \\
\text { pharmaceutical industry }\end{array}$ & 19 & 15.8 & 13 & 28.8 & 0.05 & $0.46(0.20-1.04)$ \\
\hline
\end{tabular}


41 months. Canosa ${ }^{10}$ described that the average time between presentation of studies at a conference and their publication was 27 months, similar to the 28 months observed by Weitz. ${ }^{11}$ These periods are shorter than the one found in our study because they take into account the time between the presentation of results in a conference and their publication, instead of the time between the project submission and its publication, which also includes high variations that depend on the nature and length of each project. Moreover, such logical extension in the time required until publication may result in an underestimation of the proportion of published projects because a higher scientific output of institutions will be observed in the last years of a study.

Shamliyam ${ }^{12}$ described that experimental studies were published more often than observational ones, while Weber ${ }^{13}$ found that study characteristics are not predictors of authors' intent to publish. We found that studies with any type of funding had a higher possibility of publication. Most likely, having financial support may be related to projects that have a higher feasibility and the necessary support at the time of going through the editorial process.

In our study, problems with funding and an insufficient sample size were the most common limitations for completing a project referred by investigators. It is worth noting that $10 \%$ of unpublished results were related to an "insufficient sample size," thus highlighting the importance of making a precise (or even ample) estimation at this stage of the project. In line with the observations made in other studies, ${ }^{6,13}$ lack of time was the most common barrier in relation to the presentation or publication of the results obtained in completed studies. Six percent of survey respondents who did not publish their studies indicated that they "considered that results were not significant." It would be interesting to find out if respondents selected this option because they found neither positive nor relevant results. In the first instance, they may be contributing to the positive results bias, while in the second instance, the situation points out their inconsistency at the time of establishing the objective of the project. In a review on pediatric publication barriers, Van Cleave ${ }^{14}$ found difficulties across the entire research process, including the identification of a study subject matter, the selection of a methodological design and the preparation of the manuscript.
When knowledge obtained from scientific research only gets presented in conferences, it becomes unavailable for the rest of the medical community. When research results are not published or are selectively published based on result trend or robustness, health care professionals are not capable of basing their decisions on the whole body of evidence. ${ }^{15}$

The results obtained in our study, supported by a high completion rate $(91.2 \%)$ of the survey which reduces potential biases, indicate the need to establish strategies aimed at improving the research process.

The inclusion of research activities during residency increases participation in scientific actions, improves opportunities related to new specialties, promotes interest in a research career and encourages the search of bibliography in databases, thus becoming a complement for professional training. ${ }^{16,17}$ In our hospital, a research training program for residents has been in place since 1996, with interesting achievements; ${ }^{18}$ this program may even be partially responsible for the increase observed in the scientific output over the past five years included in this study.

However, such program is only targeted to training professionals, so it is necessary to offer activities that will involve the rest of the hospital community. Some of the strategies that could be considered at an institutional level include creating a critical reading group focused on scientific articles, offering guidance on methodology and statistics, and providing training on scientific writing.

Assessing the completion rate of approved projects and the publication rate of completed projects are two aspects that help to evaluate the scientific output of an institution. On the one hand, it allows to indirectly observe the feasibility of studies, which should be considered by institutional review boards, and on the other, it allows to have an idea of the degree of commitment by the research team, a major factor at the time of allocating resources. However, in the end, research quality and its impact on everyday practice are the actual measurements of the scientific output of a health institution.

\section{CONCLUSIONS}

Of all projects submitted to the institutional review board, $60.9 \%$ were completed; of them, $78.3 \%$ were presented in scientific meetings and $37.5 \%$ were published. Drug trials were most 
likely not to be completed. Studies that received funding and multicenter studies had a higher chance of being published.

\section{REFERENCES}

1. Polit DF, Hungler BP. Investigación científica en ciencias de la salud. 5a ed. México: Mc Graw-Hill Interamericana; 1997.

2. Rodriguez SP, Vassallo J, Berlín V, Kulik V, Grenoville M. Factores asociados con la aprobación; desarrollo y publicación de proyectos de investigación en un hospital pediátrico. Arch Argent Pediatr 2009;107(6):504-9.

3. Manjarin M, Di Lalla S, Baño G, Ossorio MF, Ferrero F. Participación del Hospital General de Niños Pedro de Elizalde en los Congresos Argentinos de Pediatría. Rev Pediatr Elizalde 2009;19(1):9-13.

4. Domínguez P, Seoane M, Ossorio M, Ferrero F. Participación de los hospitales pediátricos de la Ciudad de Buenos Aires en las reuniones de la Sociedad Latinoamericana de Investigación Pediátrica y proporción de los trabajos que alcanzaron la publicación completa. Rev Pediatr Elizalde 2010;1(1):14-16.

5. Domínguez PA, Davenport MC, Del Valle MP, Di Lalla SE, et al. Participación del Hospital General de Niños Pedro de Elizalde en las publicaciones científicas de Archivos Argentinos de Pediatría de 1995 a 2009. Rev Pediatr Elizalde 2010;1(2):83-7.

6. Harling L, Craig W, Russell K. Factors influencing the publication of randomized controlled trials in child health research. Arch Pediatr Adolesc Med 2004;158: 983-7.

7. Carroll A, Sox C, Tarini B, Ringold S, Christakis D. Does presentation format at the Pediatric Academic Societies' AnnualMeeting predictsubsequent publication? Pediatrics 2003;112:1238-41.
8. Von Elm E, Costanza M, Walder B, Tramer M. More insight into the fate of biomedical meeting abstracts: a systematic review. BMC Med Res Methodol 2003;3:12.

9. Otero P. El proceso de inclusión de Archivos en la base de datos Medline. Arch Argent Pediatr 2009;107(1):1-3.

10. Canosa D, Ferrero F, Melamud A, Otero PD, et al. Full-text publication of abstracts presented at the 33th Argentinean Pediatric Meeting and non publication related factors. Arch Argent Pediatr 2011;109(1):56-9.

11. Weitz J, Silva H. Presentación versus publicación: Análisis de trabajos presentados en Congresos Chilenos de Gastroenterología 1998 a 2002. Gastr Latinoam 2005;16(3):287-92.

12. Shamliyan T, Kane R. Clinical research involving children: registration, completeness and publication. Pediatrics 2012;129(5):1291-300.

13. Weber EJ, Callaham ML, Wears RL, Barton C, Young G. Unpublished research from a medical specialty meeting: why investigators fail to publish. JAMA 1998;280:257-9.

14. Van Cleave J, Dougherty D, Perrin J. Strategies for addressing barriers to publishing pediatric quality improvement research. Pediatrics 2011;128(3):678-86.

15. Christakis DA, Rivara FP. Publication ethics: editors' perspectives. J Pediatr 2006;149(1 Suppl):S39-S42.

16. Vinci RJ, Bauchner $H$. Research during pediatric residency training: outcome of a senior resident block rotation. Pediatrics 2009;124(4):1126-34.

17. Kurahara D, Kogachi K. A pediatric residency research requirement to Improve collaborative resident and faculty publication productivity. Hawaii J Med Public Health 2012;71(8):224-8

18. Manjarin M, Cutri A, Noguerol E, Torres F, et al. Enseñanza de la investigación con un sistema de tutores durante la residencia de pediatría. Arch Argent Pediatr 2007;105(4):333-41. 


\section{ANNEX. \\ Survey administered to participating investigators}

\section{SURVEY: ASSESSMENT OF THE SCIENTIFIC OUTPUT OF HGNPE, 1995-2011}

Please, mark with an " $\mathrm{X}$ " the corresponding answer (only one option per question)

1. What is the current status of your research project?

$\square$ Completed

$\square$ Put off

$\square$ Cancelled

$\square$ Ongoing

2. Was your project submitted in a scientific meeting?

$\square$ Yes

3. If "Yes," indicate the name/s, date and place of the meeting/s:

4. Was your project published in a scientific journal?

$\square$ Yes

5. If "Yes," indicate the name and date of publication:

6. What do you think was the main reason for not completing or publishing your research project?

$\square$ Lack of interest

Lack of time

$\square$ Disagreement among authors

$\square$ Other studies with similar or contradictory results

$\square$ You considered that results were not significant

$\square$ Insufficient sample size

$\square$ Problems with the statistical analysis

$\square$ Pessimism among authors regarding acceptance for publication

$\square$ Problems with funding

$\square$ Not accepted for publication

$\square$ Other reasons 